\title{
Prevalence and risk factors of hepatitis $B$ virus infection in Middle-Limburg Belgium, year 2017: Importance of migration
}

\author{
Özgür M. Koc ${ }^{1,2,3}$ @ | Cécile Kremer ${ }^{4}$ | Rob Bielen ${ }^{1,2}$ | Dana Buscchots ${ }^{1,2}$ | \\ Niel Hens ${ }^{4,5}$ | Frederik Nevens ${ }^{6}$ | Geert Robaeys ${ }^{1,2,6}$
}

${ }^{1}$ Department of Gastro-Enterology and Hepatology, Ziekenhuis Oost-Limburg, Genk, Belgium

${ }^{2}$ Faculty of Medicine and Life Sciences, Hasselt University, Hasselt, Belgium

${ }^{3}$ Department of Medical Microbiology, School of Nutrition and Translational Research in Metabolism, Maastricht University Medical Centre, Maastricht, The Netherlands

${ }^{4}$ Interuniversity Institute for Biostatistics and Statistical Bioinformatics (I-Biostat), Hasselt University, Hasselt, Belgium

${ }^{5}$ Centre for Health Economic Research and Modelling Infectious Diseases, Vaccine and Infectious Disease Institute, University of Antwerp, Antwerp, Belgium

${ }^{6}$ Department of Gastro-Enterology and Hepatology, KU Leuven, Leuven, Belgium

\section{Correspondence}

Özgür M Koc, MD, Department of Gastro-enterology and Hepatology, Ziekenhuis Oost-Limburg, Schiepse Bos 6, 3600 Genk, Belgium.

Email: ozgur.koc@uhasselt.be

Funding information

Gilead Sciences, Grant/Award Number: V-2112

\begin{abstract}
Background and Aim: The hepatitis B virus (HBV) prevalence study performed in 2003 in Belgium is believed to be underestimating HBV prevalence due to underrepresentation of the non-Belgian population. Therefore, we assessed the prevalence and risk factors of $\mathrm{HBV}$ infection in a multi-ethnic region situated in Middle-Limburg Belgium, in 2017.

Methods: Between May and November 2017, blood samples and questionnaires were taken from patients who presented at the emergency department of a large educational hospital. Blood samples were tested for hepatitis B surface antigen (HBsAg) and hepatitis B core antibodies (anti-HBc). A sample size of 1000 persons was required to obtain a representative sample of the general Middle-Limburg population.

Results: Of the 1131 patients screened, the overall HBsAg prevalence was $0.97 \%$ with differences between Belgians (0.67\%) and first-generation-migrants (2.55\%), $(P=0.015)$. Five (45.5\%) of $11 \mathrm{HBsAg}$-positive individuals were not aware of their HBV status. All five (100\%) newly diagnosed HBsAg-positive patients had further clinical evaluation and all had a normal level of alanine aminotransferase (ALT). The prevalence of anti-HBc was $8.4 \%$, and was significantly associated with age-genderethnicity interaction, presence of HBV-infected household member, hepatitis $\mathrm{C}$ virus infection, men who have sex with men, and hemodialysis.

Conclusions: In this area with large immigrant populations, we found a higher prevalence of HBV infection compared with the nationwide study of 2003. National HBV screening for first-generation migrants is needed as this high-risk group will go unnoticed due to the possible incorrect interpretation of normal ALT values.

KEYWORDS

Belgium, hepatitis $\mathrm{B}$, migrants, prevalence, risk factors
\end{abstract}

\section{1 | INTRODUCTION}

Hepatitis B virus (HBV) remains a global health problem given that an estimated two billion people have been exposed to this virus and 257 million people live with chronic HBV infection worldwide in the year 2017. ${ }^{1}$ Since the onset of HBV infection is generally asymptomatic, many of the HBV-infected patients may not be aware of their infection status, thereby increasing the likelihood of infecting others. $^{2}$ Chronic HBV infection was also responsible for up to 887000 deaths in 2015, making it together with hepatitis $C$ virus (HCV) infection the seventh leading cause of mortality worldwide., ${ }^{1,3}$

The prevalence of chronic HBV varies upon the geographic distribution, from high-prevalence areas (>8\% hepatitis B surface antigen ( $\mathrm{HBsAg}$ ) positive), to intermediate-prevalence areas (2\%-7\% 
$\mathrm{HBsAg}$ positive) and low-prevalence areas ( $<2 \% \mathrm{HBsAg}$ positive). ${ }^{4}$ Western Europe is among the low-prevalence areas, but subgroups of higher HBV prevalence may exist in regions with large immigrant populations. Even though migrants comprise only one in 20 European citizens, they account for one in four of all chronic HBV infections. In Belgium, 52\% of chronic HBV cases are estimated to be among migrants from intermediate- and high-prevalence areas. This number is even greater than $70 \%$ in countries such as Austria, Ireland, the Netherlands, and UK. ${ }^{5}$

Both prevalence studies in Flanders (Belgium), one in 1993 to 1994 and one in 2003, showed that $0.7 \%$ of the population was HBsAg positive. ${ }^{6,7}$ However, the prevalence of chronic HBV infection in the population-based study in 2003 is believed to be an underestimation due to underrepresentation of the non-Belgian population. Moreover, there are no data regarding the predominant risk factors for HBV infection in the Belgian general population. The recognized risk factors of $\mathrm{HBV}$ infection include having an $\mathrm{HBsAg}$ positive mother, HBsAg-positive close family member, HBsAgpositive sex partner, multiple (unsafe) heterosexual contacts, men who have sex with men (MSM), intravenous drug use (IDU), blood or blood-product transfusion, hemodialysis, invasive healthcare procedure or dental treatment, and tattooing or body piercing. ${ }^{8}$

Even in low-prevalence areas such as Belgium, HBV prevention and control is a public health priority, particularly since safe and effective vaccines are available. In addition to primary prevention, recent advancements in the treatment of chronic HBV infection now allow secondary prevention., ${ }^{9,10}$

Since chronic HBV infections are often asymptomatic, seroepidemiological studies are needed (1) to understand the extent and importance of this public health problem, (2) to identify population subgroups with an increased prevalence of infection, and (3) to foresee its future impact on the health system and ensure an adequate allocation of financial resources.

The aim of the present study was to evaluate the current prevalence and risk factors of HBV infection in a multiethnic region situated in Middle-Limburg Belgium.

\section{2 | PATIENTS AND METHODS}

\section{1 | Study population and sample design}

This epidemiological study was conducted in a multiethnic region of about 240803 inhabitants in the region of Middle-Limburg between May and November 2017. All patients between the age of 18 and 70 who presented at the emergency department of a large educational hospital were eligible for this study. Upon written informed consent a blood sample was taken and a face-to-face questionnaire, assessing demographics (age, gender, country of birth, and mother's country of birth), known viral hepatitis status (HBV positive, $\mathrm{HCV}$ positive, and HIV positive), and risk factors was performed. These risk factors included having an HBsAg-positive close family member, multiple (unsafe) sexual contacts, MSM, IDU, blood or blood-product transfusion, hemodialysis, invasive healthcare procedure or dental treatment (ie, surgery), healthcare worker, cultural or ritual intervention, and tattooing or body piercing. Immigrants who were not born in Belgium were considered first-generation migrants (FGMs).

Trained personnel collected a blood sample for serological testing for each patient. The Ziekenhuis Oost-Limburg laboratories tested all blood samples for HBsAg and hepatitis B core antibodies (anti-HBc) using an electrochemiluminescence assay (Cobas 8000 e602, Roche, Germany). The interpretation of positive and negative results was carried out as recommended by the test producer.

The culturally targeted, multilingual (Dutch-, English- and Turkish-speaking) first author attempted to contact persons with HBsAg-positive results via telephone 1 week after their screening. At least six attempts at three different times of the day were made. Persons not reached within 6 months were considered lost to followup. The first author encouraged and invited all newly diagnosed HBsAg-positive patients to enter an Outpatient Hepatology Department. A clinical work-up and treatment program was proposed for newly diagnosed patients based on European Association for the Study of the Liver (EASL) guidelines. ${ }^{11}$

\subsection{Ethics approval and trial registration}

The study was approved by the local Medical Ethical Committees $(16 / 072 \mathrm{U})$, and was conducted in accordance with the provisions of the Declaration of Helsinki and its amendments. Good clinical practice guidelines were followed throughout the study. The study is registered at clinicaltrials.gov (NCT03425513).

\section{3 | Statistical analyses}

Sample size calculation was performed with the aid of Epi Info (Version 7.2.1.0, Atlanta, GA). The number of patients needed per ethnicity was calculated so that the results of the sample group agreed with those of the Middle-Limburg population with a confidence interval $(\mathrm{Cl})$ of $95 \%$. The expected frequency for FGMs was $21 \%$ (Limburg in cijfers, personal communication). The sample size calculation suggested a total of 1000 tested persons would need to be included.

Survey data were entered bed-side into a secure electronic database Castor EDC (Castor Electronic Data Capture, Ciwit Bv, Amsterdam, the Netherlands). Analysis of variance (ANOVA) was used to test for differences in mean age and prevalence between different ethnic groups.

For calculating the effect of universal HBV vaccination in Belgium, we stratified $\mathrm{HBsAg}$ and/or anti-HBc prevalence into two birth cohorts (born before 1987 and born after 1987). The cutoff was chosen as the vaccination program since September 1999 with catchup vaccination for one age cohort with the age range of 10 to 13 years covered children born after $1987 .{ }^{12}$

To correct for differences between the sample and the MiddleLimburg population, weighted tests were conducted. Weighting was done based on the combination of age and ethnicity (Belgian vs nonBelgian, ie, FGM). ${ }^{13}$ Weighted $\chi^{2}$ tests were used to assess significant 
associations between the evaluated risk factors and HBsAg or anti$\mathrm{HBc}$ prevalence. Risk factors that were shown to be significantly associated $(P<0.10)$ to $\mathrm{HBsAg}$ or anti-HBc in these univariate analyses were included in a weighted multiple logistic regression model. In these models, Firth's bias adjustment was used to account for data sparseness. ${ }^{14}$ Model reduction was done in a backward stepwise manner based on the 0.05 significance level.

Several classification methods were also applied to the data on anti-HBc positivity for prediction purposes. First, a simple classification tree was constructed based on an almost completely balanced training data set (ie, $40 \%$ of the subjects were anti-HBc positive) to identify characteristics that explain the outcome in the best way. Bagging and random forests were then used in an attempt to improve the error rate of this classification tree. Since the predictions based on (almost) balanced data overestimated the true proportion of anti$\mathrm{HBc}$ positives, a correction was made. ${ }^{15}$ The classification models were then compared to the weighted logistic regression model in terms of prediction accuracy. Data analyses were performed using RStudio (Version 1.0.136, Boston, MA).

\section{3 | RESULTS}

\section{1 | Characteristics of the study population}

Of the 1537 individuals invited, 1131 (73.6\%) completed the questionnaire and donated blood. The study included 605 men (53.5\%) and 526 women (46.5\%), with a mean age of 46 years $(95 \%$ $\mathrm{Cl}, 45.2-46.9$ years). FGMs comprised $20.8 \%$ of the study population. FGMs were mainly born in the Netherlands (32.8\%), Turkey (18.7\%), and Italy (12.3\%). Gender distribution was similar in both ethnic groups (Belgian and FGM, $P=0.629$ ). When compared with the Belgian patients (mean age of 46 years, $95 \% \mathrm{Cl}, 45.0-46.9$ years), FGMs (mean age of 47 years, $95 \% \mathrm{Cl}, 44.8-48.3$ years) were not significantly older $(P=0.536)$.

Patients who refused participation had a mean age of 48 years (95\% $\mathrm{Cl}$, 43.3-46.3 years) and $52.1 \%$ were male. This did not significantly differ from patients willing to participate $(P=0.135$ and $P=0.699$ for age and gender, respectively). Reasons for not participating were: fear of needles (14.5\%), too sick (26.9\%), other worries than testing (27.3\%), does not want to know viral hepatitis status (8.1\%), already participating in a lot of studies $(0.3 \%)$, and other (22.9\%).

\section{2 | Prevalence of anti-HBc antibodies}

In two patients, blood sample volumes were insufficient for testing and in 22 patients, no anti-HBc blood sample was taken. Anti-HBc positivity was $8.4 \%$ among the remaining 1107 participants. Anti-HBc prevalence in Belgian individuals born after 1987 was $1.6 \%$. This number was higher for those born before 1987 (7.0\%, $P=0.001)$. Current or past HBV infection in FGMs was apparent in 49 of 231 (21.2\%) with differences in those born in the Netherlands ( 5 of $75,6.7 \%$ ), Turkey (16 of $44,36.4 \%$ ), Italy ( 8 of $28,28.6 \%$ ), other low endemic countries ( 2 of $30,6.7 \%$ ) and other intermediate or high endemic countries (18 of 54,
33.3\%), $P<0.001$. In the weighted $\chi^{2}$ tests, age-gender-ethnicity interaction $(P<0.001)$, not shown in table), living with an HBV-infected person $(P<0.001)$, HCV infection $(P=0.004)$, MSM $(P=0.001)$, blood transfusion before $1972(P=0.026)$, hemodialysis $(P<0.001)$, cultural or ritual intervention $(P=0.015)$ and having a tattoo or body piercing $(P=0.041)$ were significantly associated with current or past HBV infection, that is, anti-HBc positivity (Table 1 ).

Since only 2 of 7 patients that have had a blood transfusion before 1972 were anti-HBc positive, this risk factor was not included in any further analyses. Parameter estimates of the weighted multiple logistic regression model are shown in Table 2 . It can be seen that, compared with 18 to 39 years old Belgian females, there was a significantly increased risk of anti-HBc positivity in all FGMs, as well as in 40 to 70 years old Belgian females $(P=0.039)$. Young Belgian males had a lower risk of anti-HBc positivity, although not statistically significant. Furthermore, living with an HBV-infected person $(P<0.001)$, reporting HCV infection $(P=0.005)$, being on hemodialysis treatment $(P<0.001)$, and being MSM $(P=0.002)$ appeared to be associated with a higher risk of anti-HBc positivity.

\subsection{Anti-HBc classification models}

In growing the classification tree, only the risk factors that were shown to be significantly associated $(P<0.10)$ to anti-HBc prevalence (in the weighted $\chi^{2}$ tests) were used as input (except for having received a blood transfusion before 1972, for the same reason mentioned above). The obtained classification tree is shown in Figure 1. The predictive accuracy of this tree was $73.0 \%$ based on the ROC curve (see solid line in Figure 2), with a sensitivity of $57.1 \%$ and specificity of $80.1 \%$. The predictive accuracy was also calculated for the weighted logistic regression model, giving a predictive accuracy of $77.5 \%$ with a sensitivity and specificity of $68.8 \%$ and $77.8 \%$, respectively. From Figure 2 it can be concluded that the weighted logistic regression model using Firth's bias adjustment performed best in predicting anti-HBC prevalence in this study.

\section{4 | Prevalence of $\mathrm{HBsAg}$}

Of the 1131 patients tested, 11 (1.0\%) were HBsAg positive. Five (45.5\%) HBsAg-positive patients were born in Belgium, two (18.2\%) in Italy, one (9.1\%) in Turkey, and three $(27.2 \%)$ in other intermediate or high endemic countries (one in Saudi Arabia, Iran, and Kenya), $P=0.136$. None of the HBsAg-positive patients were younger than 30 years of age (born after 1987) compared with 11 HBsAg-positive patients born before $1987, P=0.282$. The $\mathrm{HBsAg}$ prevalence in FGMs was $2.55 \%$ (6 of 235), with differences in those born in the Netherlands ( 0 of $77,0.0 \%$ ), Turkey ( 1 of 44 , $2.27 \%$ ), Italy ( 2 of $29,6.9 \%$ ), other low endemic countries ( 0 of 30 , $0.0 \%$ ) and other intermediate or high endemic countries ( 3 of 55 , 5.5\%), $P=0.285$.

Table 3 shows the prevalence of HBsAg by different risk factors. In the weighted chi squared tests, HBsAg positivity was significantly 
TABLE 1 Prevalence of anti-HBc by different risk factors (weighted $\chi^{2}$ test)

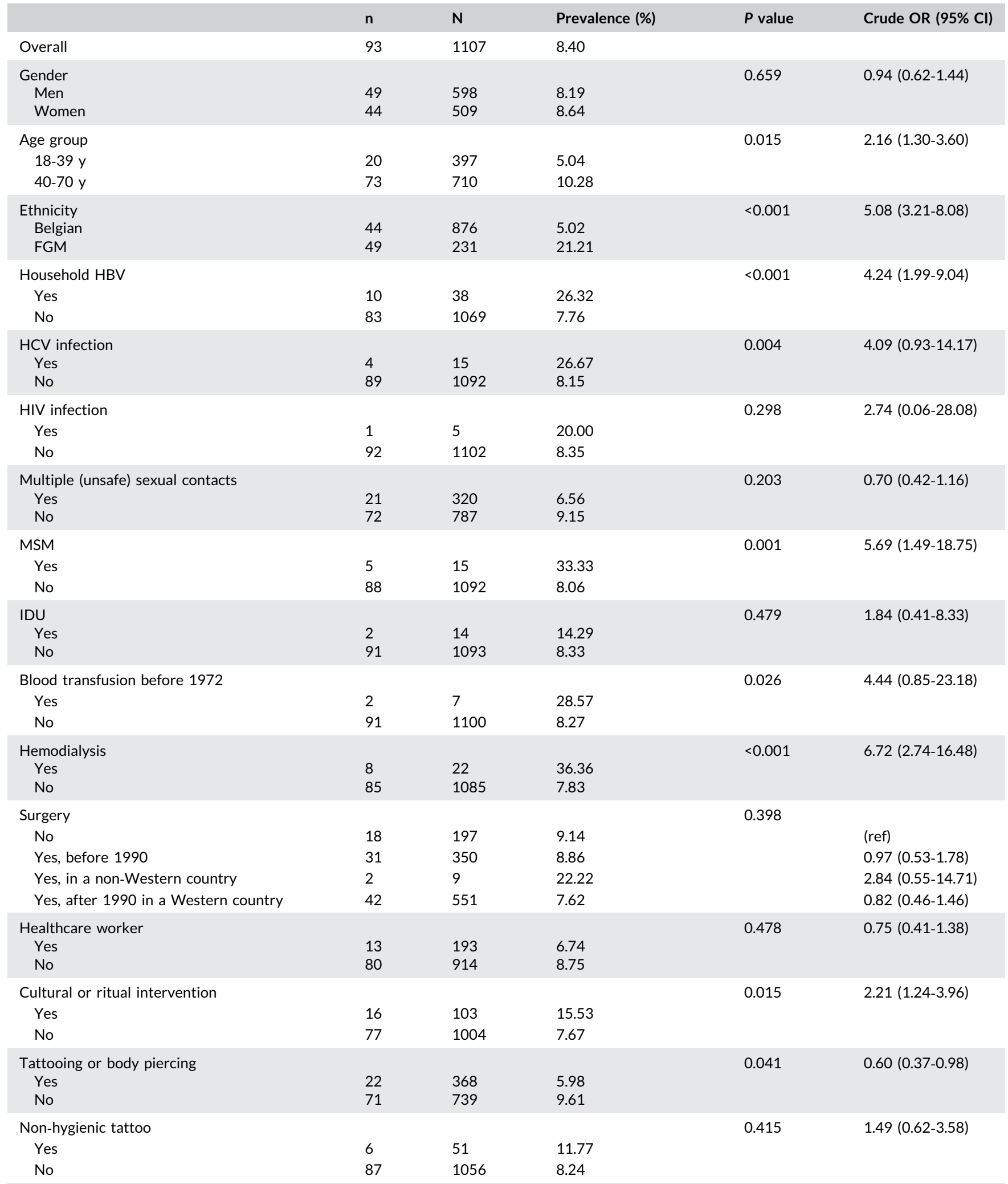

Abbreviations: anti-HBc, hepatitis B core antibodies; $\mathrm{Cl}$, confidence interval; FGM, first-generation migrants (ie, foreign-born persons); HBV, hepatitis B virus; HCV, hepatitis $C$ virus; IDU: intravenous drug use; MSM, men who have sex with men; OR, odds ratio. 
TABLE 2 Parameter estimates for the final weighted model for anti-HBC

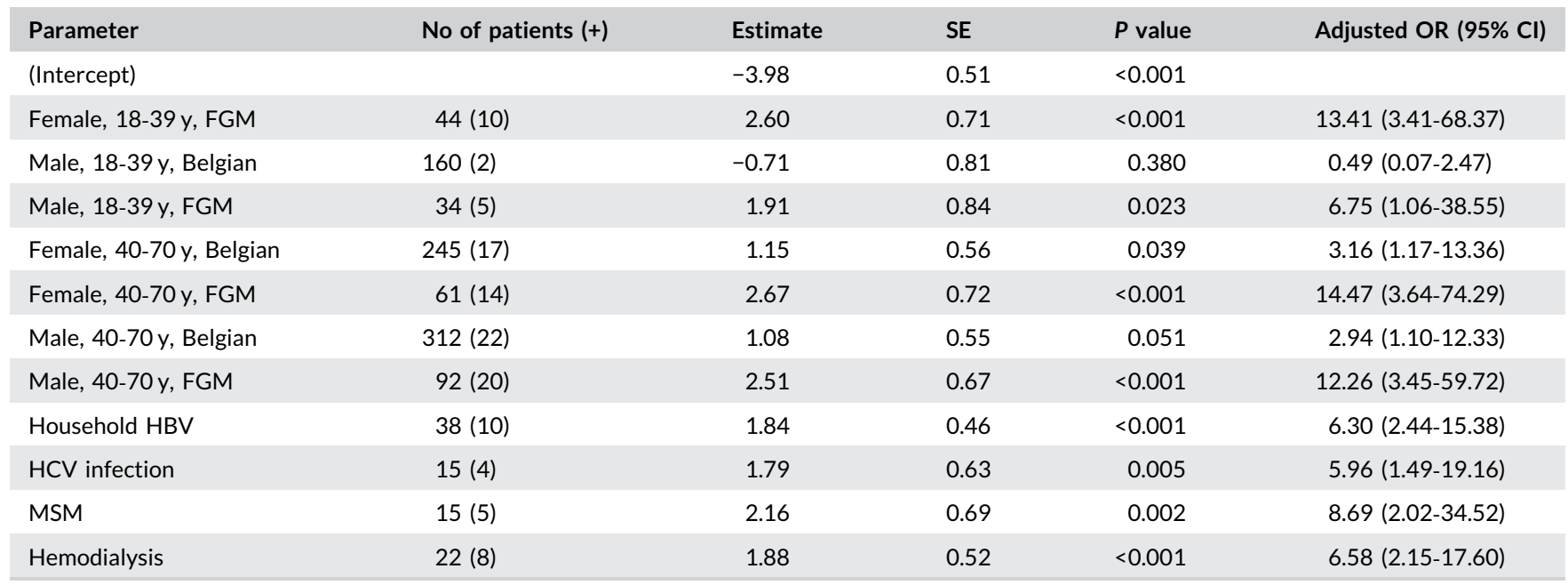

Abbreviations: anti-HBc, hepatitis B core antibodies; $\mathrm{Cl}$, confidence interval; FGM, first-generation migrants (ie, foreign-born persons); HBV, hepatitis B virus; $\mathrm{HCV}$, hepatitis $\mathrm{C}$ virus; MSM, men who have sex with men; OR, odds ratio; SE, standard error around the coefficient for the constant.

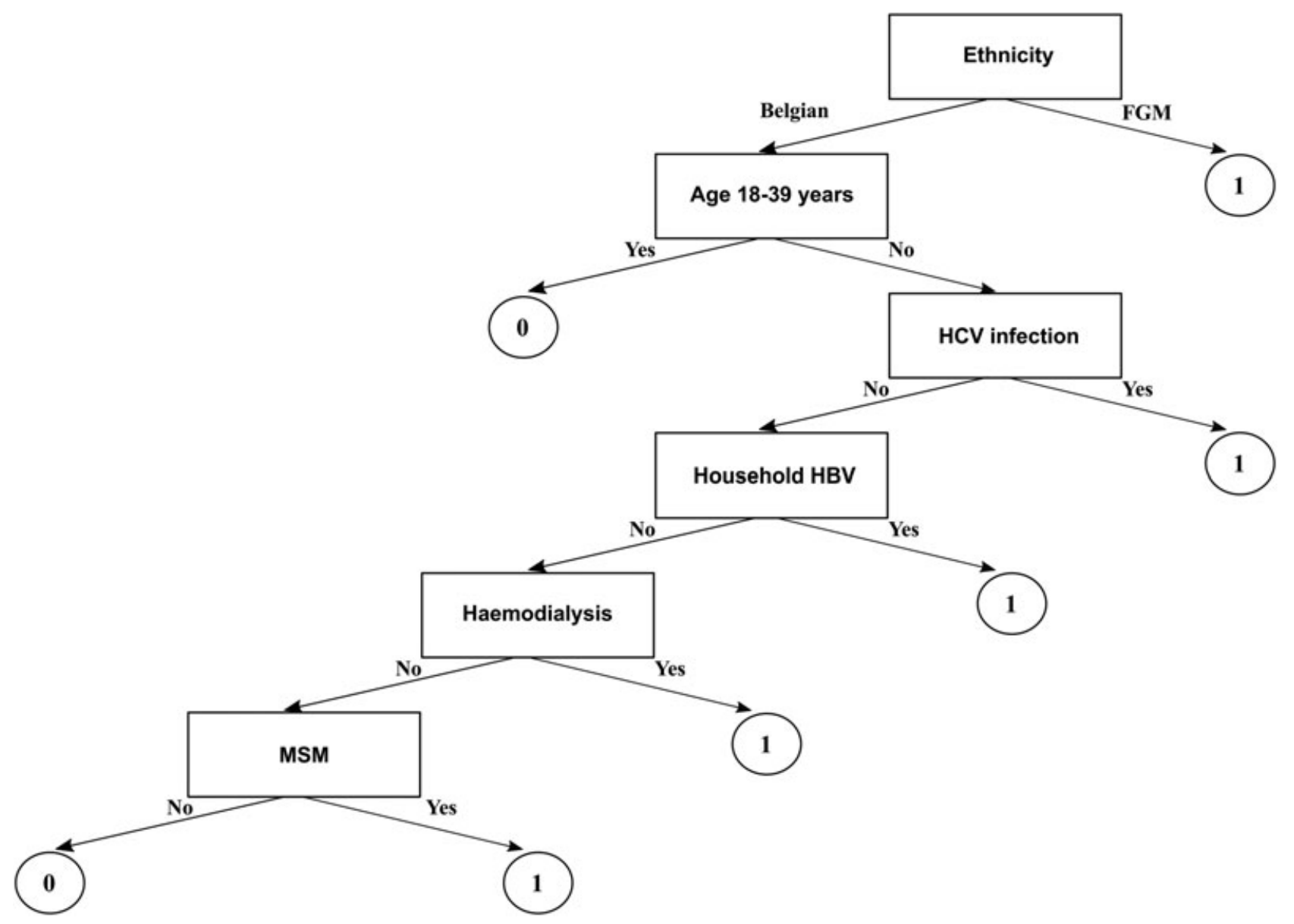

FIGURE 1 Classification tree based on (almost) balanced training sample for anti-HBc. A "O" indicates anti-HBc negative, while a "1" indicates anti-HBc positive. Anti-HBc, hepatitis B core antibodies; FGM, first-generation migrants (ie, foreign-born persons); HBV, hepatitis B virus; $\mathrm{HCV}$, hepatitis $\mathrm{C}$ virus; MSM, men who have sex with men 


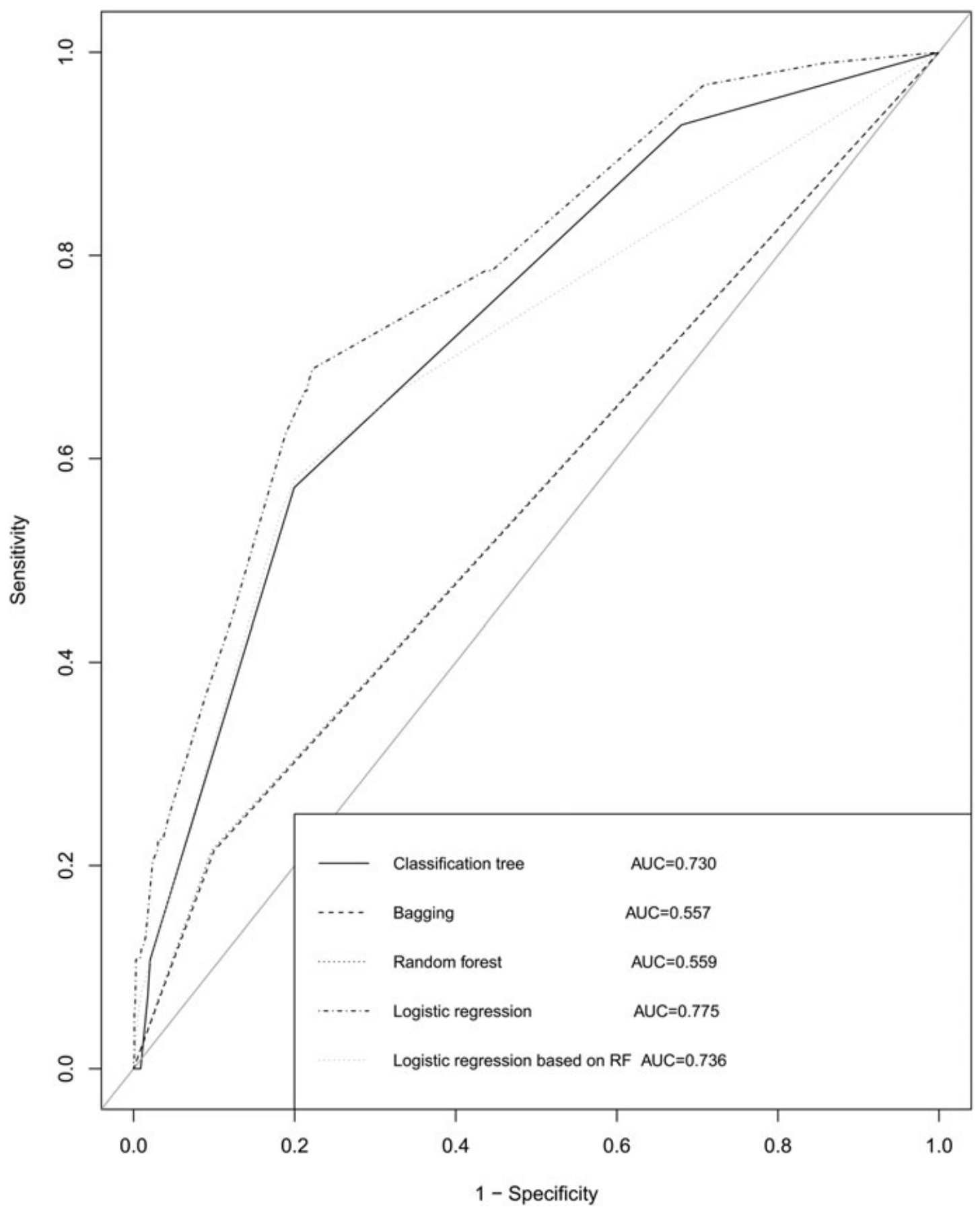

FIGURE 2 Comparison of different classification models for anti-HBc using ROC curves for which the AUC is used to quantify the predictive accuracy. In an attempt to reduce the tree misclassification error, bagging was applied. All risk factors were included and $B=400$ trees were grown. Class weights were used to correct for the (almost) balanced training sample. The predictive accuracy of this model, however, was only $55.7 \%$ (see dashed line). For the random forest model, at each iteration 12 randomly sampled risk factors were included and $B=5000$ trees were grown. Class weights were again used. The predictive accuracy of this model was slightly higher than for bagging, that is, $55.9 \%$ (see dotted line). The six most important variables from the RF analysis were included in a logistic regression model (see gray dotted line), which had a predictive accuracy of $73.6 \%$, still lower than for the abovementioned weighted logistic regression model (77.5\%, see dot-dashed line). Anti-HBc, hepatitis B core antibodies; AUC, area under the ROC curve; RF, random forest; ROC, receiver operating characteristic

associated with ethnicity $(P=0.015)$, having an HBV-infected household member $(P=0.036)$, MSM $(P=0.016)$, and tattooing or body piercing $(P=0.077)$. Logistic regression was not conducted for $\mathrm{HBsAg}$ due to the low number of chronically infected patients.

\subsection{Linkage to care}

Of the $11 \mathrm{HBsAg-positive} \mathrm{individuals,} \mathrm{five} \mathrm{(45.5 \% )} \mathrm{were} \mathrm{not} \mathrm{aware} \mathrm{of}$ their HBV status and the other six (54.5\%) were already linked to care. Thus, the percentage of newly diagnosed HBsAg-positive 
TABLE 3 Prevalence of HBsAg by different risk factors (weighted $\chi^{2}$ test)

\begin{tabular}{|c|c|c|c|c|c|}
\hline & $\mathrm{n}$ & $N$ & Prevalence (\%) & $P$ value & Crude OR $(95 \% \mathrm{Cl})$ \\
\hline Overall & 11 & 1131 & 0.97 & & \\
\hline $\begin{array}{l}\text { Gender } \\
\text { Men } \\
\text { Women }\end{array}$ & $\begin{array}{l}5 \\
6\end{array}$ & $\begin{array}{l}605 \\
526\end{array}$ & $\begin{array}{l}0.83 \\
1.14\end{array}$ & 0.744 & $1.38(0.42-4.56)$ \\
\hline $\begin{array}{l}\text { Age group } \\
18-39 \text { y } \\
40-70 \text { y }\end{array}$ & $\begin{array}{l}3 \\
8\end{array}$ & $\begin{array}{l}412 \\
719\end{array}$ & $\begin{array}{l}0.73 \\
1.11\end{array}$ & 0.581 & $1.53(0.41-5.81)$ \\
\hline $\begin{array}{l}\text { Household HBV } \\
\text { Yes } \\
\text { No }\end{array}$ & $\begin{array}{l}2 \\
9\end{array}$ & $\begin{array}{l}39 \\
1092\end{array}$ & $\begin{array}{l}5.13 \\
0.82\end{array}$ & 0.036 & $6.51(1.36-31.17)$ \\
\hline $\begin{array}{l}\text { Multiple (unsafe) sexual contacts } \\
\text { Yes } \\
\text { No }\end{array}$ & $\begin{array}{l}4 \\
7\end{array}$ & $\begin{array}{l}331 \\
800\end{array}$ & $\begin{array}{l}1.21 \\
0.88\end{array}$ & 0.498 & $1.39(0.40-4.77)$ \\
\hline $\begin{array}{l}\text { MSM } \\
\text { Yes } \\
\text { No }\end{array}$ & $\begin{array}{l}1 \\
10\end{array}$ & $\begin{array}{l}15 \\
1116\end{array}$ & $\begin{array}{l}6.67 \\
0.90\end{array}$ & 0.016 & $7.86(0.17-62.50)$ \\
\hline $\begin{array}{l}\text { IDU } \\
\text { Yes } \\
\text { No }\end{array}$ & $\begin{array}{l}0 \\
11\end{array}$ & $\begin{array}{l}15 \\
1116\end{array}$ & $\begin{array}{l}0.00 \\
0.99\end{array}$ & 0.706 & $\cdots$ \\
\hline $\begin{array}{l}\text { Surgery } \\
\text { No } \\
\text { Yes, before } 1990 \\
\text { Yes, in a non-Western country } \\
\text { Yes, after } 1990 \text { in a Western country }\end{array}$ & $\begin{array}{l}2 \\
4 \\
0 \\
5\end{array}$ & $\begin{array}{l}202 \\
354 \\
10 \\
565\end{array}$ & $\begin{array}{l}0.99 \\
1.13 \\
0.00 \\
0.89\end{array}$ & 0.944 & $\begin{array}{l}\text { (ref) } \\
1.14(0.21-6.30) \\
\cdots \\
0.89(0.17-4.64)\end{array}$ \\
\hline $\begin{array}{l}\text { Healthcare worker } \\
\text { Yes } \\
\text { No }\end{array}$ & $\begin{array}{l}1 \\
10\end{array}$ & $\begin{array}{l}196 \\
935\end{array}$ & $\begin{array}{l}0.51 \\
1.07\end{array}$ & 0.572 & $0.47(0.06-3.73)$ \\
\hline $\begin{array}{l}\text { Cultural or ritual intervention } \\
\text { Yes } \\
\text { No }\end{array}$ & $\begin{array}{l}1 \\
10\end{array}$ & $\begin{array}{l}103 \\
1028\end{array}$ & $\begin{array}{l}0.97 \\
0.97\end{array}$ & 0.846 & $1.00(0.13-7.88)$ \\
\hline $\begin{array}{l}\text { Tattooing or body piercing } \\
\text { Yes } \\
\text { No }\end{array}$ & $\begin{array}{l}1 \\
10\end{array}$ & $\begin{array}{l}377 \\
754\end{array}$ & $\begin{array}{l}0.27 \\
1.33\end{array}$ & 0.077 & $0.20(0.03-1.55)$ \\
\hline $\begin{array}{l}\text { Non-hygienic tattoo } \\
\text { Yes } \\
\text { No }\end{array}$ & $\begin{array}{l}1 \\
10\end{array}$ & $\begin{array}{l}51 \\
1080\end{array}$ & $\begin{array}{l}1.96 \\
0.93\end{array}$ & 0.629 & $2.14(0.27-17.05)$ \\
\hline
\end{tabular}

Abbreviations: $\mathrm{Cl}$, confidence interval; FGM, first-generation migrants (ie, foreign-born persons); HBsAg, hepatitis B surface antigen; HBV, hepatitis B virus; HCV, hepatitis C virus; IDU, intravenous drug use; MSM, men who have sex with men; OR, odds ratio. 
patients was $0.44 \%$ (5 of 1131). All five (100\%) patients had further clinical evaluation which revealed that all had a normal level of alanine aminotransferase (ALT $<40 \mathrm{U} / \mathrm{L}$ ), all were hepatitis $\mathrm{B}$ e antigen (HBeAg) negative, all had HBV DNA levels below $2000 \mathrm{IU} /$ $\mathrm{mL}$, all had fibrosis score F0-1 according to Metavir score, and none had evidence of liver cirrhosis on ultrasound. One of the five patients is currently being treated prophylactically in the Outpatient Hepatology Department before and during the administration of chemotherapy according to the EASL guidelines.

\section{4 | DISCUSSION}

This is the first study to assess the seroprevalence of HBV infection in a multi-ethnic Belgian region including a considerably large proportion of foreign-born individuals. Besides estimating the seroprevalence in a multiethnic region, risk factors associated to HBV infection were evaluated, which may assist physicians, public health practitioners, and policymakers in eliminating hepatitis B as a public health threat by $2030 .{ }^{16}$

The principal findings of the present study can be summarized as follows. First, there was an overall HBsAg seroprevalence of $1.0 \%$, with higher prevalence in FGMs (2.55\%) compared with Belgians (0.7\%). Second, none of the HBsAg-positive patients were born after 1987. Third, an anti-HBc prevalence of $8.4 \%$ was found in the multiethnic region situated in Middle-Limburg with age-gender-ethnicity interaction, having an HBV-infected household member, reporting $\mathrm{HCV}$ infection, being MSM, and ever having been on hemodialysis treatment being significantly associated with past or current HBV infection. Fourth, this study demonstrated an excellent linkage to care with five of 11 (45.5\%) HBsAg-positive individuals not being aware of their HBV status and further clinical evaluation showing normal levels of ALT in all five patients.

In this study, about $1.0 \%$ of all patients appeared to be $\mathrm{HBsAg}$ positive and $8.4 \%$ showed evidence of HBV exposure. To date, the overall prevalence in Belgium was estimated to be lower, that is, $0.7 \%$ positive for $\mathrm{HBsAg}$ and $6.4 \%$ positive for anti-HBc. ${ }^{6,7}$ This discrepancy can be explained by the fact that both of these previous epidemiological studies also included individuals aged 0 to 17 years. Moreover, selection bias can explain a possible underestimation in 2003 as the recruiting of participants in the general population by mail probably missed people from certain risk groups (eg, migrants). In the present study, we included patients aged 18 to 70 years who presented at the emergency department of a large educational hospital in a multi-ethnic region situated in Middle-Limburg. Furthermore, the region of Middle-Limburg has a large immigrant population, with $20.8 \%$ of the study population being FGMs, in contrast to $8.0 \%$ in Flanders, Belgium. In this respect, we found a higher $\mathrm{HBsAg}$ prevalence in FGMs and especially in those born in intermediate or high endemic countries, highlighting the fact that migrants are an important risk group for chronic HBV infection. ${ }^{17,18}$

The HBsAg prevalence in the general population of the neighboring countries ranges from $0.1 \%$ in Ireland to $0.8 \%$ in Spain. ${ }^{19}$ In line with our findings, a higher HBV prevalence was found in FGMs born in intermediate- or high-prevalence areas in comparison to the native population of countries such as France, Germany, the Netherlands, and Spain. ${ }^{20-23}$

The impact of implementation of a universal free-of-charge hepatitis $B$ vaccination in Belgium was also apparent from the results of the current study. None of the HBsAg-positive patients were born after year 1987. Anti-HBc prevalence was also lower in Belgian individuals born after 1987, when compared with those born before 1987. After all, universal infant hepatitis B vaccination with catch-up in adolescents aged 10 to 13 years began in September 1999 in Belgium. ${ }^{12}$ Consequently, the vaccination program covered children born after 1987. To evaluate the effects of a universal HBV vaccination program in less than 20-year old, prevalence of seroprotection and HBV infection were assessed by Theeten et al. ${ }^{24}$ They demonstrated that the prevalence of HBV infection remained low in Belgium and that overall high levels of "vaccinated" serostatus were achieved in infants as well as in adolescents.

We also analysed the risk factors associated to anti-HBc positivity. The most prominent risk factors were being FGM and age between 40 and 70 years (except for Belgian males), having an HBV-infected household member, reporting HCV infection, being MSM, and ever having received hemodialysis, with $22.22 \%, 26.32 \%$, $26.67 \%, 33.33 \%$, and $36.36 \%$ testing positive for anti-HBc, respectively. A comparison of different classification methods revealed that the weighted logistic regression model performed best in classifying patients as either anti-HBc positive or negative, although the identified risk factors in this model were the same as those found in a classification tree analysis.

The implementation of a culturally and linguistically appropriate healthcare provider in the present study could explain the high linkage to care of newly diagnosed HBsAg-positive patients. ${ }^{25}$ Moreover, all newly diagnosed HBsAg-positive patients underwent ALT determination and normal ALT levels were found in all of them. The Belgian nationwide epidemiological data support the findings of our study and emphasized that $80 \%$ of the newly diagnosed chronic HBV patients had normal ALT levels at diagnosis. ${ }^{26}$ A major limitation of ALT as a biochemical marker of liver disease is that its levels often fluctuate over time during the variable course of chronic HBV infection and may fail to identify patients with necroinflammatory activity or fibrosis. ${ }^{27}$

There are some limitations to the present study. First, by screening at the emergency department, a bias toward subjects in certain risk groups may occur. However, these risk groups might have been underrepresented in the previous population-based study in Belgium. ${ }^{7}$ Inclusion of certain risk groups in our study also allowed us to determine the most prominent risk factors for HBV prevalence in Belgium for the first time. Second, due to logistical factors (eg, limited daily enrollment time, limited study research team) not every eligible participant could be informed about the study. Third, a concern is that, even though the patients' demographics, known viral hepatitis status and risk factors were recorded, certain risk behaviors could have been underreported as the questionnaire was performed using a face-to-face interview. Inferences from this study should also be 
drawn with caution since it is difficult to establish causal pathways from cross-sectional studies as our present study. Thus, we have attempted only to identify risk factors associated with HBV infection using odds ratios. This study could also be underpowered to find significant associations between certain risk factors and $\mathrm{HBsAg}$ or anti-HBc, as the study was powered in such a way that the distribution per ethnicity was similar to that of the Middle-Limburg population, and not to specific risk factors. However, good predictive accuracy was shown for the weighted multiple logistic regression model, providing evidence for the significant impact of abovementioned risk factors for anti-HBc.

In conclusion, this study shows that the HBsAg and anti-HBc seroprevalences in a multi-ethnic region in Middle-Limburg are higher than those previously found nationwide, probably because high-risk groups such as FGMs are more present. Since all newly diagnosed HBsAg-positive patients had normal levels of ALT, national HBV screening for individuals born in intermediate or high endemic countries is needed as this high-risk group will go unnoticed due to the possible incorrect interpretation of normal ALT values. To adapt or to adopt screening practices and preventive measures, seroepidemiological studies should not only be done nationwide but also locally in multi-ethnic regions.

\section{ACKNOWLEDGMENTS}

This study is part of the "Limburg Clinical Research Program" (LCRP), supported by the foundation Limburg Sterk Merk, province of Limburg, Flemish government, Hasselt University, Ziekenhuis OostLimburg, and Jessa Hospital. The funding source had no role in the design and conduct of the study; collection, management, analysis, and interpretation of the data; preparation, review, or approval of the manuscript; and decision to submit the manuscript for publication. This study was supported by the Gilead Sciences by an unrestricted grant registered as $\mathrm{V}-2112$ at Hasselt University.

\section{AUTHOR CONTRIBUTIONS}

ÖMK, CK, RB, DB, NH, FN, and GR contributed to the conception and design of the study. ÖMK and RB were involved in planning and GR supervised the work. ÖMK and RB collected the data. CK performed the analysis. ÖMK drafted the first version of the paper, the coauthors critically revised the article and approved the final version, including the authorship list.

\section{CONFLICT OF INTERESTS}

ÖK has received a travel grant and research grants from Gilead. RB has received travel grants from Abbvie, MSD, and Gilead to attend scientific congresses and research grants from Gilead and MSD. GR has received research grants from Abbvie, MSD, Janssen Pharmaceuticals, and has acted as a consultant/advisor for Abbvie, MSD, Gilead, and BMS. The other authors declare that there are no conflict of interests.

\section{ORCID}

Özgür M. Koc (D) http://orcid.org/0000-0003-3678-5703

\section{REFERENCES}

1. World Health Organization. Hepatitis B. Geneva, Switzerland: World Health Organization; 2018. http://www.who.int/mediacentre/ factsheets/fs204/en/. Accessed January 21, 2019.

2. Lin SY, Chang ET, So SK. Why we should routinely screen Asian American adults for hepatitis B: a cross-sectional study of Asians in California. Hepatology. 2007;46(4):1034-1040.

3. Stanaway JD, Flaxman AD, Naghavi M, et al. The global burden of viral hepatitis from 1990 to 2013: findings from the Global Burden of Disease Study 2013. Lancet. 2016;388(10049):1081-1088.

4. Mahoney FJ. Update on diagnosis, management, and prevention of hepatitis B virus infection. Clin Microbiol Rev. 1999;12(2):351-366.

5. Ahmad AA, Falla AM, Duffell E, et al. Estimating the scale of chronic hepatitis $B$ virus infection among migrants in EU/EEA countries. BMC Infect Dis. 2018;18(1):34.

6. Beutels M, Van Damme P, Aelvoet W, et al. Prevalence of hepatitis A, $B$ and $C$ in the Flemish population. Eur J Epidemiol. 1997; 13(3):275-280.

7. Quoilin S, Hutse V, Vandenberghe $H$, et al. A population-based prevalence study of hepatitis $A, B$ and $C$ virus using oral fluid in Flanders, Belgium. Eur J Epidemiol. 2007;22(3):195-202.

8. Chu CJ, Keeffe EB, Han SH, et al. Hepatitis B virus genotypes in the United States: results of a nationwide study. Gastroenterology. 2003;125(2):444-451.

9. Janssen HL, van Zonneveld M, Senturk H, et al. Pegylated interferon alfa-2b alone or in combination with lamivudine for $\mathrm{HBeAg-positive}$ chronic hepatitis B: a randomised trial. Lancet. 2005;365(9454): 123-129.

10. Lok AS, McMahon BJ, Brown RS, Jr., et al. Antiviral therapy for chronic hepatitis $B$ viral infection in adults: a systematic review and meta-analysis. Hepatology. 2016;63(1):284-306.

11. EASL. Clinical Practice Guidelines on the management of hepatitis $B$ virus infection. J Hepatol. 2017;67:2017-2398.

12. Van Kerschaver Erwin. The Belgian Expanded Programme on Immunization (EPI) and hepatitis B vaccination, Southern African. J Epidemiol Infect. 2008;23(1):40-44.

13. Centraal Bureau voor de Statistiek. Bevolking; leeftijd, migratieachtergrond, geslacht en regio. Den Haag, the Netherlands: Centraal Bureau voor de Statistiek; 2018. http://statline.cbs.nl/Statweb/ publication/?DM=SLNL\&PA=37713\&D1=1-2,7-8\&D2=0\&D3=1,3-4\& $\mathrm{D} 4=16 \& D 5=\mid \& H D R=G 4, T, G 1, G 2 \& S T B=G 3 \& V W=T$. Accessed May 22, 2018.

14. Firth D. Bias reduction of maximum likelihood estimates. Biometrika. 1993;80(1):27-38.

15. Lemmens A, Croux C. Bagging and boosting classification trees to predict churn. J Mark Res. 2006;43(2):276-286.

16. World health organization. Combating hepatitis $B$ and $C$ to reach elimination by 2030. Geneva, Switzerland: World Health Organization; 2016. Accessed May 22, 2018. http://apps.who.int/iris/ bitstream/10665/206453/1/WHO_HIV_2016.04_eng.pdf?ua=1

17. Rossi C, Shrier I, Marshall L, et al. Seroprevalence of chronic hepatitis $B$ virus infection and prior immunity in immigrants and refugees: a systematic review and meta-analysis. PLOS One. 2012;7(9):e44611.

18. Kowdley KV, Wang CC, Welch S, Roberts $\mathrm{H}$, Brosgart CL. Prevalence of chronic hepatitis B among foreign-born persons living in the United States by country of origin. Hepatology. 2012;56(2):422-433.

19. European Centre for Disease Prevention and Control. Systematic review on hepatitis B and C prevalence in the EU/EEA. Stockholm: ECDC; 2016. 
20. Meffre C, Le Strat $Y$, Delarocque-Astagneau E, et al. Prevalence of hepatitis B and hepatitis $C$ virus infections in France in 2004: social factors are important predictors after adjusting for known risk factors. J Med Virol. 2010;82(4):546-555.

21. Wolffram I, Petroff D, Batz O, et al. Prevalence of elevated ALT values, $\mathrm{HBsAg}$, and anti-HCV in the primary care setting and evaluation of guideline defined hepatitis risk scenarios. J Hepatol. 2015;62(6):1256-1264.

22. Hahne SJ, De Melker HE, Kretzschmar M, et al. Prevalence of hepatitis B virus infection in The Netherlands in 1996 and 2007. Epidemiol Infect. 2012;140(8):1469-1480.

23. Pedraza-Flechas AM, Garcia-Comas L, Ordobas-Gavin M, et al. Hepatitis B virus infection and vaccine-induced immunity in Madrid (Spain). Gaceta sanitaria/SESPAS. 2014;28(6):492-495.

24. Theeten $H$, Hutse $V$, Hoppenbrouwers $K$, Beutels $P$, Van Damme P. Universal hepatitis $B$ vaccination in Belgium: impact on serological markers 3 and 7 years after implementation. Epidemiol Infect. 2014;142(2):251-261.

25. Perumalswami PV, Factor SH, Kapelusznik L, et al. Hepatitis Outreach Network: a practical strategy for hepatitis screening with linkage to care in foreign-born communities. J Hepatol. 2013; 58(5):890-897.

26. De Vroey B, Moreno C, Laleman W, et al. Hepatitis B virus and hepatitis $C$ virus infections in Belgium: similarities and differences in epidemics and initial management. Eur J Gastroenterol Hepatol. 2013;25(5):613-619.

27. Papatheodoridis GV, Manolakopoulos S, Liaw YF, Lok A. Follow-up and indications for liver biopsy in $\mathrm{HBeAg-negative} \mathrm{chronic} \mathrm{hepatitis} B$ virus infection with persistently normal ALT: a systematic review. J Hepatol. 2012;57(1):196-202.

How to cite this article: Koc ÖM, Kremer C, Bielen R, et al. Prevalence and risk factors of hepatitis $B$ virus infection in Middle-Limburg Belgium, year 2017: Importance of migration.

J Med Virol. 2019;1-10. https://doi.org/10.1002/jmv.25457 